\title{
MONITORING AND DETERMINATION OF IRRIGATION DEMAND IN CYPRUS
}

\author{
G. PAPADAVID ${ }^{1}$ \\ G. KOUNTIOS ${ }^{2}$ \\ A. MICHAILIDIS ${ }^{2, *}$
}

\author{
${ }^{1}$ Agricultural Research Institute of Cyprus, \\ 1516, Nicosia, Cyprus \\ ${ }^{2}$ Aristotle University of Thessaloniki \\ Faculty of Agriculture \\ 541 24, Thessaloniki, Greece
}

Received: 05/04/11

Accepted: 29/06/12 *to whom all correspondence should be addressed: e-mail: tassosm@auth.gr

\begin{abstract}
This technical paper describes and interprets the main results of an original research project, which integrates technological tools for developing a complete system for monitoring and determining irrigation demand on a systematic basis in Cyprus. More specifically, the main contribution of this paper consists in the estimation of evapotranspiration (ET) in Cyprus and furthermore in the undertaking of the required measures for a sustainable irrigation water management in the future. The determination of ET is a very difficult procedure, since it combines various meteorological and field parameters, while quite many different estimation models have been indicated in the literature. In this case study, a wireless sensor network is proposed to act as a monitoring tool for providing measurements of the necessary parameters (meteorological, climatic and other auxiliary data required to be included in the irrigation demand models) while reflectance is being determined directly from the satellite images. Geographic Information Systems (GIS) have been used to create a database for the collected data. Taking in to account the great importance of irrigation water as a principal driver in rural development, as well as the increasing demand for irrigation water, the investigation of ways for irrigation water management is extremely valuable, especially in waterscarce areas.
\end{abstract}

KEYWORDS: agricultural extension, evapotranspiration, irrigation, precision agriculture, remote sensing, waterware software.

\section{INTRODUCTION}

Optimal use of irrigation water plays a significant role in increasing land productivity (Ahmad et al., 2009; Hongjun et al., 2008) and feeding the earth's growing population (Cai et al., 2003).. At the same time, the irrigation water global demand is increasing following the expand of the irrigated land. Recent figures point to the fact that Irrigated areas have increased rapidly, over the last 30 years, and more than $70 \%$ of diverted water goes to the agricultural sector (Bjornlund et al., 2009). According to Michailidis et al., 2009, one of the main components of the water balance is the water loss via evapotranspiration (ET), which is proportional - among others - to the vegetation cover of a region.

Contemporary tools of precision agriculture, remote sensing (RS) and GIS techniques have played a vital role in applications regarding water management and identification of irrigated area (Nahry et al., 2011) and classification of the vegetation coverage. In light of precision agriculture, RS and GIS techniques have played a vital role in applications regarding water management and irrigation (Nahry et al., 2011). However, despite these theoretical advances, access to and use of RS data by end users require considerable technical knowledge over computing and RS, which is still a challenge (Moreenthaler et al., 2003). Additionally, a cost of applying precision agriculture is much higher than traditional one and thus any related investing decision has to be followed by strong potentials. 
The main objective of this technical paper is to present the main results of an original research project, which describes and applies a procedure for monitoring and improving the performance of on-demand irrigation networks. In particular, the application of the procedure is based on the integration of RS techniques and simulation modeling of irrigation water in Cyprus, which is facing severe droughts throughout the year. Multi-spectral satellite images are used to infer crop potential $E T$, which is a main input for water balance simulations. The need for estimating ET in Cyprus, is imposed in order to determine the exact quantity of irrigated water needed for each specific crops. The over use of water for irrigation has resulted in strong stressing for the water resources in the country. The determination of ET for irrigation purposes will be used as a vital tool for supporting the decision-making process in the management of water resources, on a technocratic level, and on the other hand will have a positive effect on the rest of water resources of Cyprus. Intended purpose is to estimate potential ET using remotely sensed data (satellite imagery) and ground meteorological data (wireless sensor network). This data will be transformed into ET maps using GIS. Final goal is to provide policy makers with accurate data, regarding irrigation management, for determining irrigation demand in Cyprus.

\section{LITERATURE REVIEW}

A consistent effort has been made in the field of agricultural research to improve the understanding of physical processes involved in an irrigation system (Feddes et al., 1988; Menenti, 1989; Michailidis and Mattas, 2007). With the water resources shortage being a basic issue for many countries, management of the available water resources is one of the greatest challenges of the 21st century. The agricultural sector is one of the major consumers of water, accounting for more than $70 \%$ of the world's fresh water (Michailidis et al., 2011). Thus, the use of irrigation water plays a significant part in increasing land productivity (Ahmad et al., 2008). According to Azzali et al. (2001), the spreading of modeling techniques using distributed parameters has largely encouraged the use of input data from remote sensing with the support of GIS systems for manipulating large data sets in irrigation water management, while Menteti et al. (1989), D'Urso et al. (1992), Bastiaanssen (2000), Ambast et al. (2006) and Papadavid et al. (2011) have indicated the potentiality of multispectral satellite images for the appraisal of irrigation management. Estimation of crop water parameters using remote sensing techniques is an expanding research field and development trends have been progressing since 1970s (Jackson et al., 1977; Seguin and Itier, 1983). Since then, remote sensing has played an increasing role in the field of hydrology and especially water management. The integration of remotely sensed data with auxiliary ground truth data for obtaining better results is common in literature. (Bastiaanssen et al., 1998; Bastiaanssen et al., 2003; Ambast et al., 2006; Minaccapili et al., 2008). It is considered that the resolution in time and space of remotely sensed data is vital in water management (Schultz et al., 2001). The rationalistic use of surface water and the monitoring of consumptive use of water by applying remote sensing techniques has been a topic of great interest for irrigation water policy makers (Tasumi et al., 2003).

The use of remote sensed data is very useful for the deployment of water strategies because it can offer a huge amount of information in short time, compared to conventional methods. Besides convenience and time reducing, remotely sensed data lessens the costs for data acquisition, especially when the area is extended (Thiruvengadachari et al., 1997). Ambast et al. (2006) have shown that the application of remote sensing data in irrigation is of high importance because it supports management of irrigation and is a powerful tool in the hands of policy makers. The potentiality of remote sensing techniques in irrigation and water resource management has been widely acknowledged. It has been found that research in ETc is directed towards energy balance algorithms that use remote sensing directly to calculate input parameters and, by combining empirical relationships to physical models, to estimate the energy budget components (Courault et al., 2005; Bastiaanssen, 2005; Minaccapili et al., 2008; Papadavid et al., 2010). All the remote sensing models of this category are characterized by several approximations and need detailed experimental validations. Multispectral images are used to infer ETc, which is the main input for water balance methods-models. 


\section{RESOURCES AND METHODOLOGY}

\section{Case study}

The Paphos district area has been selected as our case study since it is the main area of agricultural production (Figure 1) in the country. The irrigation supply of the Paphos area is provided from: Asprokremmos Dam reservoir, 24 boreholes drilled in the gravel aquifers of the major river beds Dhiarizos, Xeropotamos and Ezousas rivers and the coastal calcarenite aquifer. The irrigated area near the Asprokremmos dam will be used as a pilot study in this project.

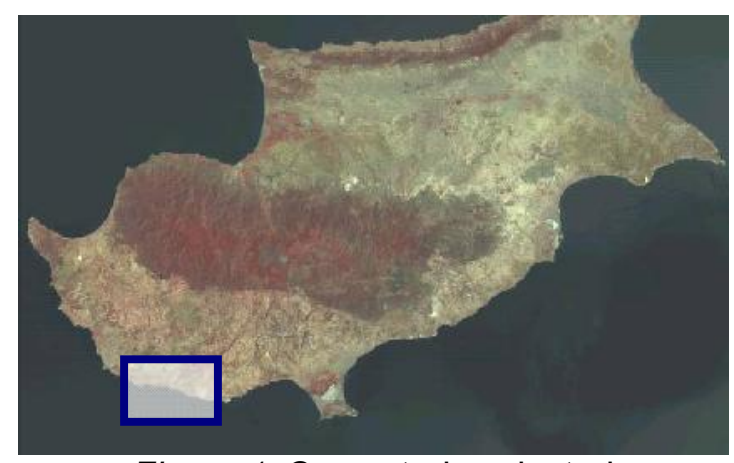

\section{Resources}

Figure 1. Case study selected

For estimating ET using FAO Penman-Monteith method, auxiliary meteorological data where used. Air temperature, atmospheric pressure, wind velocity and other data where collected from an automatic weather station, located nearby our case study (Figure 2). The auxiliary meteorological data will be the base for validating the data collected from the wireless sensors network which is installed in the fields of interest (Figure 4).
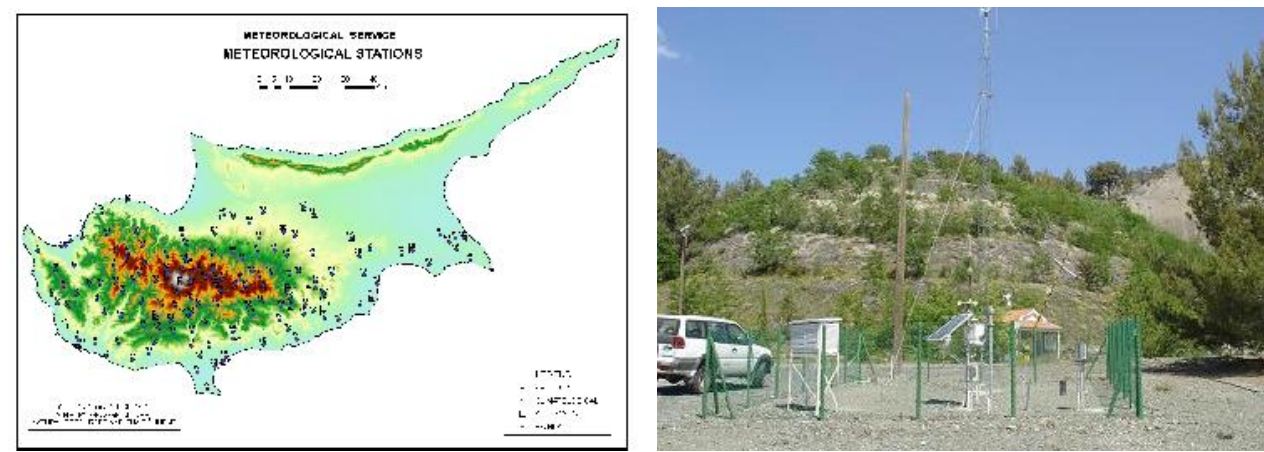

Figure 2. Map of the meteorological stations in Cyprus and an automatic weather station

Furthermore, multi-spectral, ASTER and Landsat 7 ETM+ satellite images, for the past two years have being used. For the pre-processing and processing of the satellite images the ERDAS IMAGINE software (www.erdas.com) was used. Sun-photometer and spectro-radiometer measurements were also taken in situ.
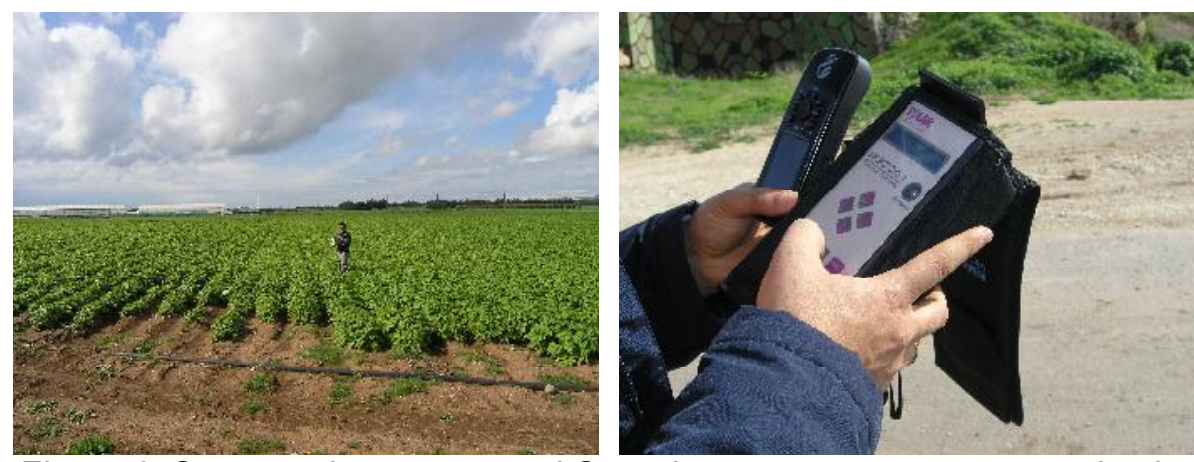

Figure 3. Spectro-photometer and Sun-photometer measurements in situ 
More specific a five-channel handheld Microtops II sun-photometer (www.slarlight.com) operated from 380 to $1020 \mathrm{~nm}$ is used (Figure 3). The sun-photometer will be used to derive the Aerosol Optical Thickness and the water vapour concentrations during the satellite overpass so as to assist the effective removal of atmospheric effects. The GER1500 field spectro-radiometer (www.spectravista.com) is also used in this research project. The GER1500 field spectroradiometers is a light-weight with high performance spectral reflectance's accuracy, covering the ultraviolet, visible and near-infrared wavelengths from $350 \mathrm{~nm}$ to $1050 \mathrm{~nm}$. GER 1500 uses a diffraction grating with a silicon diode array which has 512 discrete detectors and provides the capability to read 512 spectral bands. The instrument is very rapid scanning, acquiring spectra in milliseconds. The spectro-radiometer is used to derive the spectral reflectance values of various crops in the selected agricultural fields and to support the derivation of reflectance values from medium and high resolution images.

The Wireless Sensor Network (WSN) is consisting of a number of approximately twenty wireless nodes placed in our case study (Figure 4). The WSN acts as a wide area distributed data collection system deployed to collect and reliably transmit soil and air environmental data to a remote basestation hosted at Cyprus University of Technology (at the RS Laboratory) (Hadjimitsis et al., 2008). The sensors are deployed using ad-hoc multi-hop communication protocol and transmit their data to a gateway which is responsible to collect, save and forward them to a remote database through a GPRS connection. The solar powered gateway is equipped with various meteorology sensors required to assist the indeed research project such as rain, wind, barometric pressure, temperature etc, which give additional information to the system. The gateway also hosts a GPS sensor for identifying the exact position of the WSN an event-driven smart camera for acquiring real-time pictures of the area and also a GPRS modem for communicating with the remote server. In the future a multi-parameter decision system running on the remote server would be able to process the sensor data and produce valuable information about watering different vegetables and create early notifications and suggestions which are then distributed to farmers and water management authorities. The system would be able to process multi parameter data collected from different sensors such as soil moisture, soil temperature leaves wetness and temperature, humidity, rainfall, wind speed and direction and ambient light.

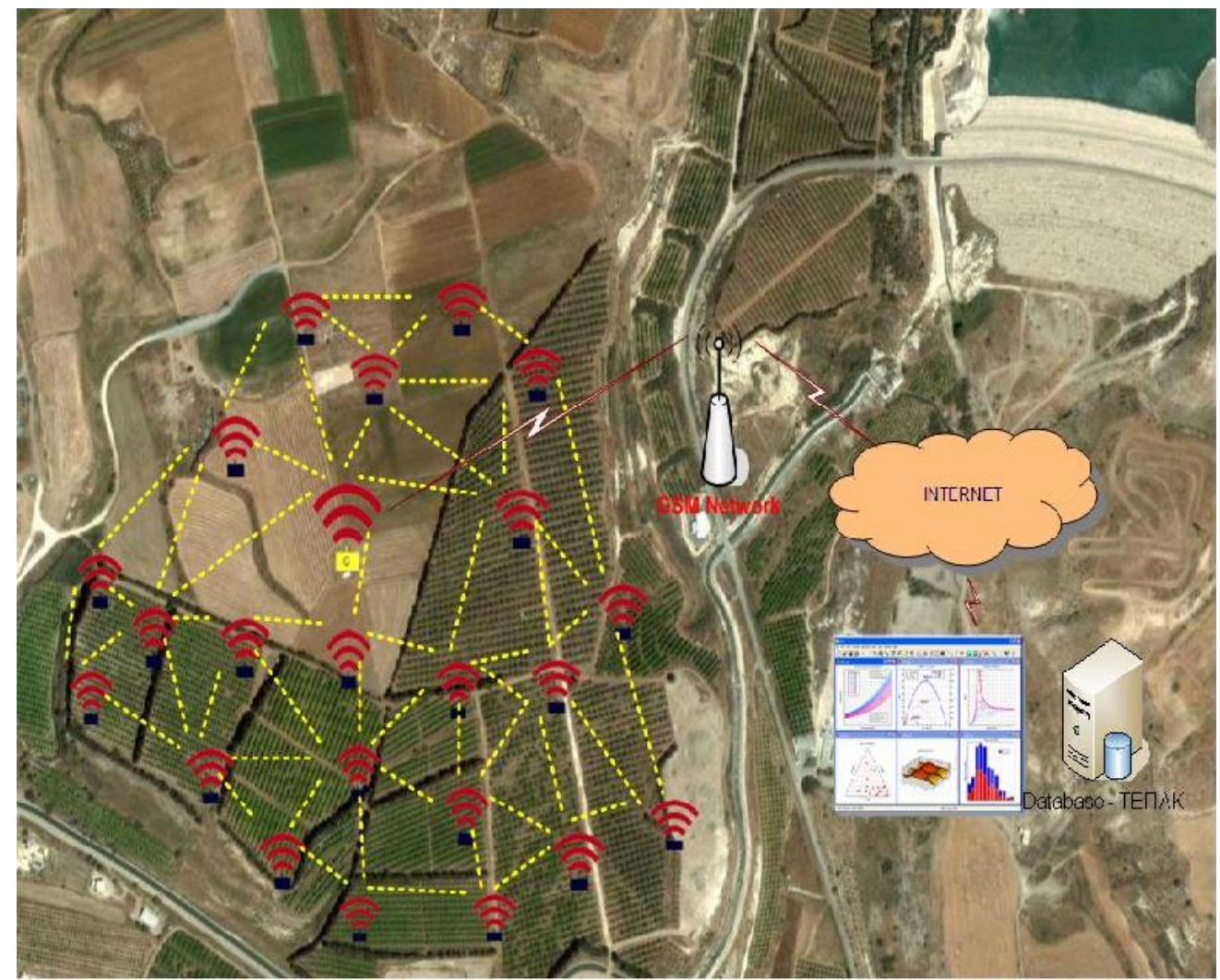

Figure 4. The Wireless Sensor Network in the AOI 


\section{Methodology}

Pre-processing and processing of the satellite images, includes geometric correction (second order polynomial transformation), georeferenced of the image using ground control points (WGS 84/UTM), radiometric correction in order to obtain the same comparable units for each image, and finally atmospheric correction by employing the darkest pixel method (histogram minimum method), to get the true reflectance of each pixel of the image (Hadjimitsis et al., 2003). Finally Liang's equation (Liang 2000) for deriving albedo was employed in this research for ASTER images. For Landsat images, weighted coefficients and irradiance were used for calculating albedo for each image (Zoran and Stefan 2006).

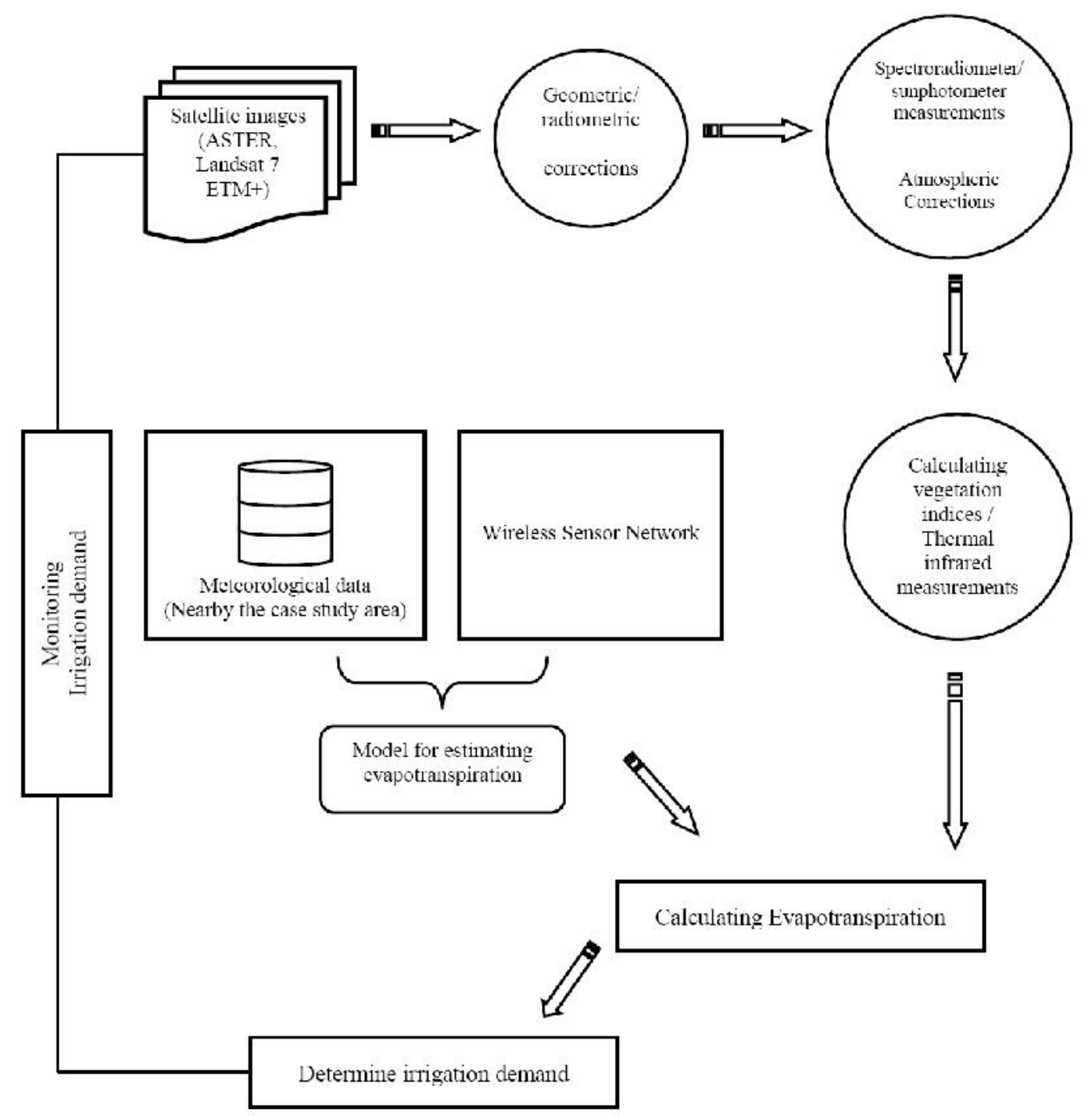

Figure 5. Methodological framework

In order to estimate ET, the one step FAO Penman-Monteith adapted to satellite data method was applied. The specific equation which is widely used to estimate ETp, under assumptions, relies on the direct application of the Penman-Monteith equation with canopy parameters estimated from satellite imagery. For estimating ET meteorological and satellite data have been used. Air temperature, atmospheric pressure, wind speed and other meteorological data were collected through the wireless sensor network which has been deployed in the fields of the study area. Satellite data, such as LAI and albedo maps (Figure 6), have been derived from satellite imagery using simplified methods (D'Urso et al., 1995). 


$$
E T_{p}=\frac{86400}{\lambda}\left[\frac{s\left(1-0.4 e^{-0.5 L A I}\right)(1-a)\left(K^{\downarrow}+L^{*}\right)+c_{p} p_{a}\left(e_{s}-e_{a}\right) U / 124}{s+\gamma(1+U / 0.62 L A I)}\right]
$$

where: $K^{\downarrow}$ is the incoming solar radiation and $U$ the wind speed; the other variables, namely $L^{*}$ (net longwave radiation), $c_{p}$ (air specific heat), $\rho_{a}$ (air density), $\left(e_{s}-e_{a}\right)$ (vapour pressure deficit), $\lambda$ (latent heat of vaporisation of water) and $\mathrm{y}$ (thermodynamic psychrometric constant) are calculated from air temperature and humidity at $2.0 \mathrm{~m}$ reference height. This equation is valid under conditions of high solar irradiance (typical summer condition in Mediterranean climate) and for LAl>0.5, which is the case of Cyprus. The height of the crops was defined from direct observations.
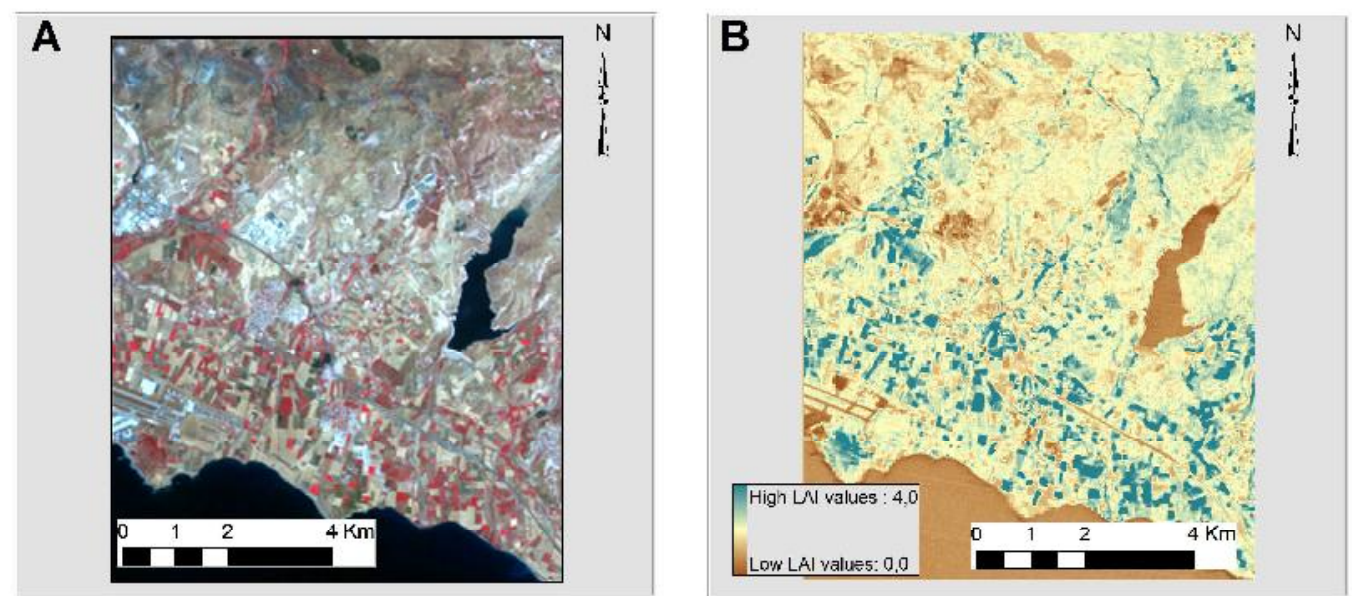

Figure 6. Example of satellite imagery (ASTER) transformance to thematic maps (here LAI map)

\section{RESULTS}

The final results have been tabulated and shown in Table 1 and graphically in Figure 7. Atmospheric correction has been found to be very critical for estimating ET. Approximately an error of $5 \%$ less than the calculated 'ETp' mean was recorded due to atmospheric effects. Figure 8 shows a presentation of ET on a satellite image for the area of interest. It is obvious that ETp is increasing during summer months.

Table 1. Results of FAO Penman-Monteith application for estimating ETp

\begin{tabular}{lllccc}
\hline No & $\begin{array}{l}\text { Date of } \\
\text { Satellite } \\
\text { image }\end{array}$ & Satellite & ETp mean & ETp max & ETp min \\
\hline 1 & $17-12-2007$ & ASTER & 2.33 & 2.36 & 2.29 \\
2 & $24-12-2007$ & ASTER & 2.34 & 2.38 & 2.27 \\
3 & $26-02-2008$ & ASTER & 2.25 & 2.27 & 2.22 \\
4 & $28-07-2008$ & LANDSAT 7 ETM+ & 2.78 & 2.85 & 2.74 \\
5 & $13-08-2008$ & LANDSAT 7 ETM+ & 2.84 & 2.88 & 2.77 \\
6 & $29-08-2008$ & LANDSAT 7 ETM+ & 3.03 & 3.07 & 2.99 \\
7 & $04-12-2008$ & ASTER & 2.65 & 2.69 & 2.60 \\
\hline
\end{tabular}

The results have provided strong evidence to support what theory illustrates: low values during winter time and high values during summer time while middle values for autumn and spring are counted. The highest values are derived in august while the lowest values in december. These results can be used in irrigation scheduling for providing the farmers with the right water requirements for their crops. Of course this procedure is a dynamic one and depends also on the meteorological data of the area. That's why the wireless sensor have been very assisting in the methodology as it was providing real time data. It has to be mentioned that the wireless sensor network is very accurate in providing meteorological data and it is calibrated every month from specialist of the cyprus university of technology. 


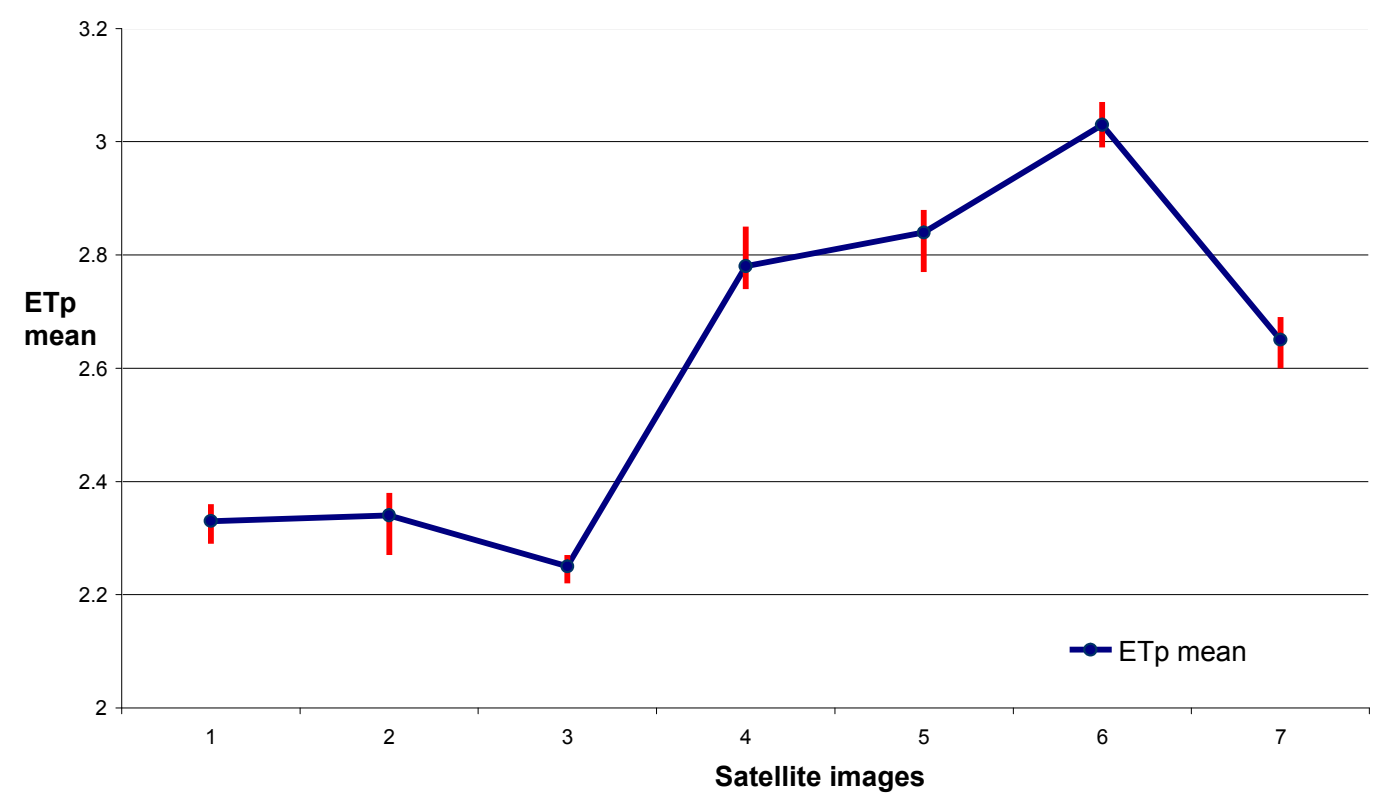

Figure 7. ETp mean diagram for each date, with their variations

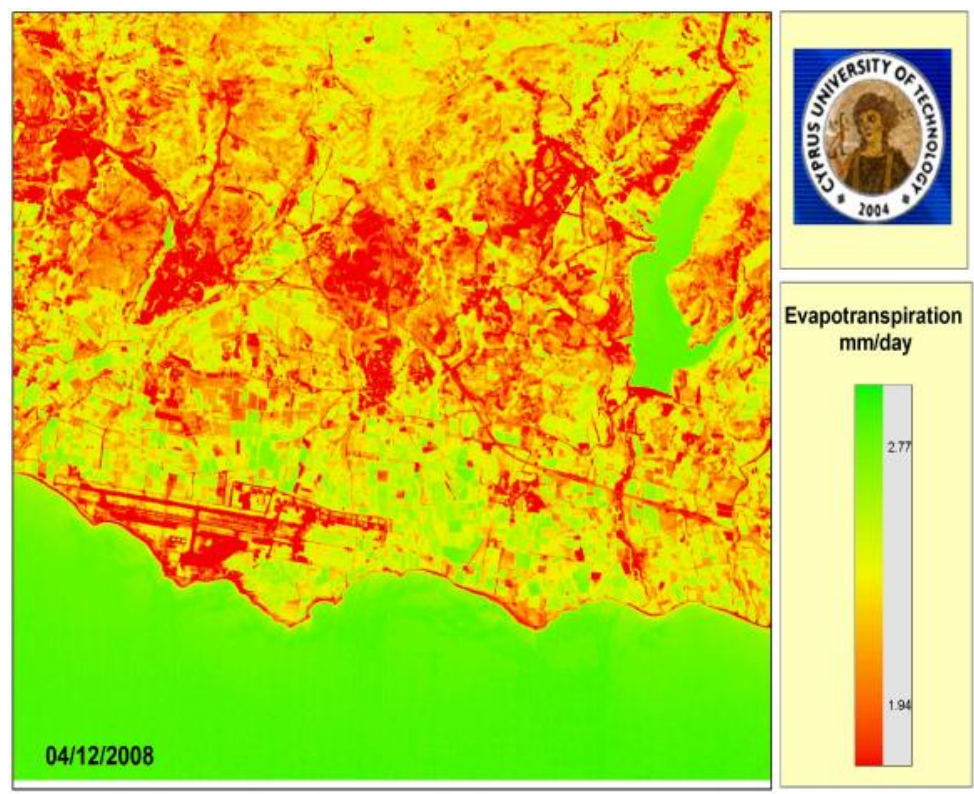

Figure 8. Map showing the ETp as calculated for ASTER images using GIS software

\section{CONCLUSIONS}

This technical paper presents some first results of the application of FAO Penman-Monteith method in the estimation of ET. For this purpose auxiliary meteorological data have been used from a wireless sensor network along with satellite images (Landsat 7 ETM+ and Aster) for providing crop canopy parameters. For more accuracy results spectro-radiometer and sun-photometer measurements have been also used. These promising results show how RS data can be used in order to calculate ETp. The main goal of this paper was to provide a novel structural tool to agricultural extension services for the monitoring and determination of irrigation demand in Cyprus. On the other hand, the application described has international relevance to several other local areas where irrigated agriculture is an important component of rural development. Actually, it is not a unique application. There are many other similar ones in several other areas, in both developed and developing countries, that rely on irrigated agriculture to some degree (Nahry et al., 2011; Mouratidis et al., 2010). Besides, most irrigators internationally express concerns about their weakness to 
estimate ET and furthermore to undertake the required measures for a sustainable irrigation water management in the future. In addition, they often express the need for information to support irrigation water efficiency improvements and the desire to make optimal use of available and limited natural resources. Thus, the application presented here could well have resonance in many other countries well beyond Cyprus. Future work consists of further validation of the results, not only using Penman-Monteith method for other cultivations but other acceptable methods and models for estimating ET.

\section{REFERENCES}

Ahmad M.D., Turral H. and Nazeer A. (2008). Diagnosing irrigation performance and water productivity through satellite remote sensing and secondary data in a large irrigation system of Pakistan, Journal of Agricultural Water Management, 96, 551-564.

Ahmad M.D., Turral H., Nazeer A. (2009). Diagnosing irrigation performance and water productivity through Remote Sensing and secondary data in a large irrigation system of Pakistan. Agricultural Water management, 96(4), 551-564.

Ambast S.K., Ashok K., Keshari Gosain A.K. (2006). Satellite remote sensing to support management of irrigation systems: concepts and approaches, Irrigation and Drainage systems, 5, 15-39.

Azzali S., Bastiaanssen W.G.M., Menteti M., De Brower H., Meijerink A.M.J., Mza J. and Zevenbergen A.W. (1991). Remote sensing and watershed modeling, Report 48, Wageningen.

Bastiaanssen W.G.M. (2000). SEBAL-based sensible and latent heat fluxes in the irrigated Gediz Basin, Turkey Journal of Hydrology, 229, 87-100.

Bastiaanssen W.G.M. and Ali S. (2003). A new crop yield forecasting model based on satellite measurements applied across the Indus Basin, Pakistan. Agriculture, Ecosystems and Environment, 94, 321-340.

Bastiaanssen W.G.M., Menenti M., Feddes R.A. and Holtslag A.A.M. (1998). A remote sensing surface energy balance algorithm for land (SEBAL), part 1: formulation, Journal of Hydrology, 212-213, 198-212.

Bastiaanssen W.G.M., Noordman E.J.M., Pelgrum H., David G., Thoreson B.P. and Allen R.G. (2005). SEBAL model with remotely sensed data to improve water resources management under actual field conditions, Journal of Irrigation and Drainage Engineering, 131(1), 85-93.

Bjornlund H., Nicol L. and Klein K.K. (2009). The adoption of improved irrigation technology and management practices-a case study of two irrigation districts in Alberta, Canada, Agricultural Water Management, 96, 121-131.

Cai X., McKinney D.C. and Rosegrant M.W. (2003). Sustainability analysis for irrigation water management in the Aral Sea region, Agricultural Systems, 76, 1043-1066.

Courault D., Seguin B. and Olioso A. (2005). Review on estimation of Evapotranspiration from remote sensing data: from empirical to modeling approaches, Irrigation and Drainage systems, 19, 223249.

D'Urso G. and Menenti M. (1995). Mapping crop coefficients in irrigated areas from Landsat TM images; Proceed. European Symposium on Satellite Remote Sensing II, Europto, Paris, sett.'95; SPIE, International Society for Optical Engineering, 2585, 41-47.

D'Urso G., Querner E.P. and Morabito J.A. (1992). Integration of hydrological simulation models with remotely sensed data: an application to irrigation management. Leuven, Belgium, 463-472.

Feddes R.A., Kabat P., Van Bakel P.J.T., Bronswijk J.J.B. and Halbertsma J. (1988). Modelling soil water dynamics in the unsaturated zone. State of the art, Journal of Hydrology, 100, 69-111.

Hadjimitsis D.G., Clayton C.R.I. and Retalis A. (2003). Darkest pixel atmospheric correction algorithm: a revised procedure for environmental applications of satellite remotely sensed imagery. In Proc. $10^{\text {th }}$ International Symposium on Remote Sensing, Barcelona, Spain.

Hadjimitsis D.G., Papadavid G. and Kounoudes A. (2008). Integrated method for monitoring irrigation demand in agricultural fields in Cyprus using satellite remote sensing and wireless sensor network. In: Proc. 4th International Conference on Information \& Communication Technologies in Bio \& Earth Sciences, 18-20 September 2008, Athens, Greece.

Hongjun L., Zheng L., Yuping L., Chunqiang L., Zhijun L. and Shengwei Z. (2008). Estimation of water consumption and crop water productivity of winter wheat in North China Plain using remote sensing technology, Journal of Agricultural Water Management, 95, 1271-1278.

Jackson R.D., Reginato R.J. and Idso S.B. (1977). Wheat canopy temperature: A practical tool for evaluating water requirements, Water Resources Research, 13(3), 651-656. 
Liang S. (2000). Narrowband to broadband conversions of land surface albedo: I Algorithms, Journal of Remote Sensing of Environment, 78, 213-238

Meneti M., Visser T.N.M., Morabito Jaovandi A. (1989). Appraisal of irrigation performance with satellite data and georeferenced information. Irrigation theory and practice, London, 785-801.

Michailidis, A., Koutsouris A. and Nastis S. (2011). Adoption of sustainable irrigation practices in water scarce areas, Bulgarian Journal of Agricultural Science, 17(5), 579-591.

Michailidis A., Mattas K., Tzouramani I. and Karamouzis D. (2009). A Socioeconomic Valuation of an Irrigation System Project Based on Real Option Analysis Approach, Water Resources Management, 23(10), 1989-1919.

Michailidis A. and Mattas K. (2007). Using Real Options Theory to Dam investment Analysis: an Application of Binomial Option Pricing Model, Water Resources Management, 21(10), 1717-1733.

Minacapilli M., lovino M., D'Urso G. (2008). A distributed agro-hydrological model for irrigation water demand assessment, Agricultural Water Management, 95, 123-132.

Moreenthaler N., Khatib and Kim B. (2003). Incorporating a constrained optimization algorithm into remote sensing/precision agriculture methodology, Acta Astronautica, 53, 429-437.

Mouratidis I., Dimopoulos G., Astaras T. and Savvidis S. (2010). Sustainable water resources management through the use of GIS technology, Global Nest Journal, 12(2), 140-151.

Nahry A.H.E., Ali R.R. and Baroudy A.A.E. (2011). An approach for precision farming under pivot irrigation system using remote sensing and GIS techniques, Agricultural Water Management, 98(4), 517-531.

Papadavid G., Hadjimitsis D., Toulios L., Michaelides S. (2011). Mapping Potatoes Crop Height and LAI through Vegetation Indices using Remote Sensing, in Cyprus, Journal of Applied Remote Sensing, 5, DOI:10.1117/1.3596388

Papadavid G., Hadjimitsis D.G., Perdikou S., Michaelides S., Toulios L., Seraphides N. (2011). Use of field spectroscopy for exploring the impact of atmospheric effects on Landsat 5 TM / 7 ETM+ satellite images intended for hydrological purposes in Cyprus, GIScience and Remote Sensing, 48(2), 280-298 (DOI:10.2747/1548-1603.48.2.280).

Schultz G. and Engman E. (2001). Present use and future perspective of remote sensing in hydrology and water management. (Proceedings of a symposium held at Santa Fe, New Mexico, USA, April 2000). IAHS Publ. no. 267, p. 545-551.

Seguin B. and Itier B. (1983). Using middy surface temperature to estimate daily evaporation from satellite thermal IR data, International Journal of Remote Sensing, 4, 371-383.

Tasumi M., Trezza R., Allen R., Wright J. (2003). Validation tests on the SEBAL Model for evapotraspiration via satellite: ICID Workshop on Remote sensing of ET.

Thiruvengadachari S. and Sakthivadivel K. (1997). Satellite remote sensing for assessment of irrigation system performance. Research Report 9, IWMI Colombo, Srilanka.

Zoran M. and Stefan S. (2006). Atmospheric and spectral corrections for estimating surface albedo from satellite data, Journal of Optoelectronics and Advanced Materials, 8, 247-251. 